\title{
Percutaneous Fixation of Thoracolumbar Fracture AO Type (A)
}

ISSN: 2576-8875

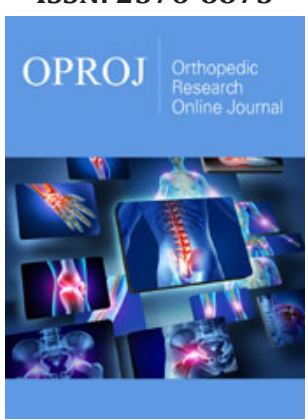

*Corresponding author: Ebeed Yasin, Orthopaedic Department, Aswan University, Egypt

Submission: 㘹 February 24, 2020

Published: 眥 February 28, 2020

Volume 6 - Issue 5

How to cite this article: Mohamed Salman MD, Faisal Adam MD, Hesham Refae MD, Ebeed Yasin MD, et al. Percutaneous Fixation of Thoracolumbar Fracture AO Type (A). Ortho Res Online J. 6(5). OPROJ.000649.2020.

DOI: 10.31031/OPROJ.2020.06.000649

Copyright@: Ebeed Yasin, This article is distributed under the terms of the Creative Commons Attribution 4.0 International License, which permits unrestricted use and redistribution provided that the original author and source are credited.
Mohamed Salman MD ${ }^{1}$, Faisal Adam MD², Hesham Refae MD ${ }^{1}$, Ahmed Shawky MD $^{2}$, Ebeed Yasin MD $^{1 *}$, Ahmed Zakaria MSc ${ }^{1}$, Ahmed Abdellatif MD ${ }^{1}$, Morsy Basiony $\mathrm{MD}^{1}$

${ }^{1}$ Orthopaedic Department, Aswan University, Egypt

${ }^{2}$ Orthopaedic Department, Assiut University Hospital, Egypt

\section{Abstract}

Background: Percutaneous method has increased in popularity in the traumatic spine field over recent 2 decades. The minimally invasive procedure has several advantages, including the diminished length of hospital stay, bleeding and early postoperative rehabilitation.

Purpose: Evaluation the clinical and functional outcomes of Percutaneous Fixation of Thoracolumbar Fracture AO Type (A).

Material: Forty patients 25 males and 15 females, Mean age 31.92 \pm 12.6 . Fall from height was in 27 patients (67.5\%) and Motor car accidents were in 13 patients (32.5\%). According to the AO classification 37 patients (92.5\%) were type A3 fracture and 3 patients (7.5\%) had type A1 fracture. All patients were neurologically free according to the ASIA score.

Methods: A prospective Cohort Study was carried out for forty patients with unstable thoracolumbar fracture AO Type A in Aswan and Assiut university hospitals for assessment of clinical and functional outcomes according to the Oswestry disability index.

Results: Forty patients with AO type A thoracolumbar fracture underwent percutaneous fixation. Surgical interference time varied from 12 to 24 hours post-traumatic, with mean 18 hours, SD of \pm 12.54 hours. Follow up for 6 months up to one year radiological, clinical and neurological status were evaluated. At the end of follow up the Oswestry disability index and ASIA score were used in the evaluation of results.

Conclusion: Percutaneous fixation is a minimally invasive, safe and reliable technique in treating cases of thoracolumbar spine fractures type A without neurology.

Keywords: Spine; Fractures; Fracture fixation; Minimally invasive; Percutaneous

\section{Introduction}

Percutaneous fixation of the thoracolumbar spine was firstly described by Magerl by using the external fixator [1]. Mathews and Long in 1995 first performed and described the lumbar percutaneous pedicle fixation technique by using a plate system instead of longitudinal rods [2]. Lowery and Kulkarni in 2000 described a new system and the rod connectors were just under the fascia they noticed good results about $61 \%$ fusion rate within 8 months [3]. In all cases, the longitudinal connectors were placed either superficially, just beneath the skin or externally. This has several potential disadvantages $1^{\text {st }}$, the superficial plate may be irritating and needs removal. $2^{\text {nd }}$, using longer screws is required than that achieved using standard pedicle systems fixation producing a less effective biomechanical stabilization and lead to more potential for failure of the implant. In Comparison with old percutaneous techniques, many new systems allow the screw placement in a perfect anatomical position. This achieves the best biomechanical stable fixation and makes the hardware stable without harmful irritating effect to the skin and muscles of the back. The percutaneous technique allows the surgeon to achieve biomechanically stable spine fixation with minimal insult to the soft tissues for many spine problems including trauma, tumor, degenerative disease and deformity $[4,5]$.

\section{Material and Methods}

Our study entails a prospective Cohort Study with preliminary results of 40 patients with thoracolumbar fracture AO type A from June 2018 to November 2019 carried out in the orthopedic departments, Aswan and Assiut university hospitals with percutaneous fixation and follow up for 6 months up to one year. The study included patients with AO type $A>30$ kyphosis, $>50 \%$ reduction of vertebral height and $<50 \%$ canal compromise. We 
excluded patients with neurology, posterior ligamentous injury. Forty patients 25 males and 15 females their age ranged between (20 to 40 years), Mean age $31.92 \pm 12.6$. Fall from height was the major cause, it was in 27 patients $(67.5 \%) \%)$ and 13 patients (32, $5 \%$ ) were Motor car accidents. According to the AO classification, 37 patients (92.5\%) had type A3 fracture and 3 patients $(7.5 \%)$ had type A1 fracture. All patients were neurologically free (grade E) according to the ASIA score. Patients who were included in the study underwent preoperative evaluation as regard history taking, clinical, neurological examination and radiographic imaging including preoperative Plain radiography, Computed Tomography and Magnetic resonance imaging for evaluation of ligamentous injury. Postoperative evaluation was done radiographically using Plain radiography immediately post-operative, Computed Tomography at 3 or 6 months postoperative and Cobb's angle was evaluated. clinically the neurological status was evaluated according to ASIA score and the Oswestry disability index was collected at 1,3,6 and12 months post-operative.

\section{Surgical technique}

We follow the technique of Sebaaly et al. [6]

1. Position: prone.

2. Anesthesia: General.

3. Skin incision is $1 \mathrm{~cm}$ lateral to pedicle margin (Figure1)

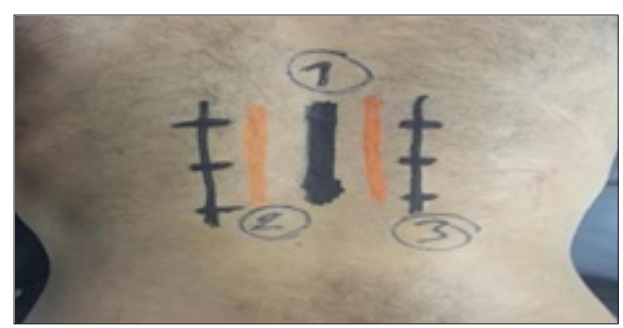

Figure 1: Illustrating:

1. The middle of the back.

2. Line parallel to the lateral edge of the pedicle.

3 . Line $1 \mathrm{~cm}$ lateral to the lateral edge of the pedicle; it's the site of the skin incision.

4. Small incisions about $2 \mathrm{~cm}$ were done (Figure 2).

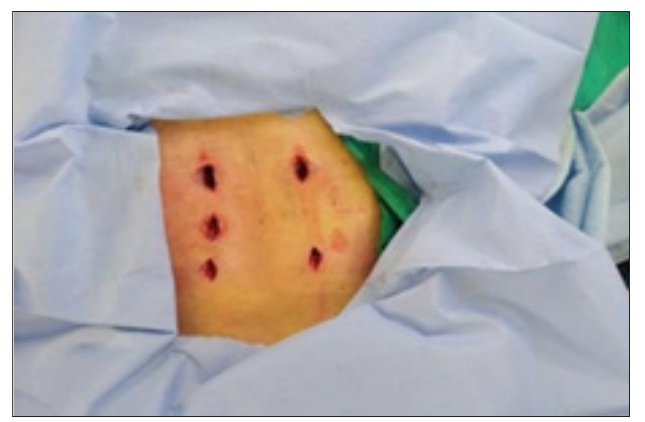

Figure 2: Illustrating skin incision in a patient undergoing percutaneous fixation with a screw at the fractured level

\section{Pedicle targeting}

Pedicle taping was done from lateral margin up to the medial margin as in AP view Figure 3. At this point, we must take a lateral view (Figure $4 \& 5$ ); it is very important step to make sure about the position of the tab cannula as it might be

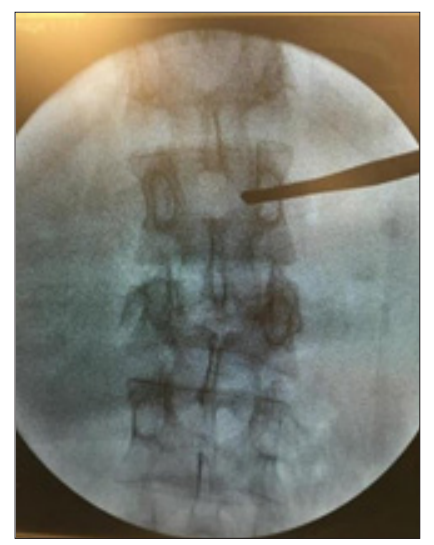

Figure 3:

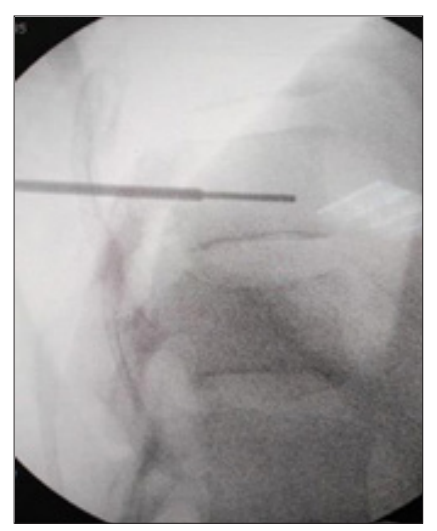

Figure 4:

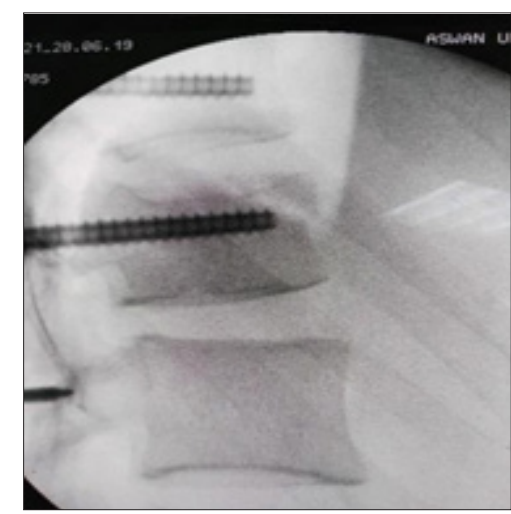

Figure 5:

a) Not reaching pedicle body junction this means its penetrating and compromising the nerve root so must take care and decrease the convergence trajectory.

b) Its end at the pedicle -body junction no crossing into body and this is the best view. 
c) It might be crossing the pedicle-body junction crossing into the body so we might increase our convergence trajectory.

6. Pedicle preparation by a combined dilator/cannula

The seven mm Dilator was inserted into the Cannula and

Until they lock on each other. Then pushing down until the dilator touches the bone. Then the dilator is removed, and we must keep the guidewire in place and must take care to avoid wire removal then Cannulated Self-Drilling Tap was advanced into the Cannula through the wire.

\section{Pedicle tapping}

We must control the tap cannula, the Self-Drilling Tap is advanced within the targeted pedicle by moving the Tap in a clockwise direction we must take care to avoid unplanned guide wire removal by avoiding advancement of the tap beyond guide wire and avoiding wire bending and breakage. Fluoroscopy used for measuring the depth of the tap and making sure that the wire is not passing the anterior cortex

\section{Screw insertion}

After the appropriate screw was chosen and loaded into polyaxial screwdriver the screw is advanced through the guidewire till the screw enter the pedicle then the wire was removed and the screw is advanced into the body but the screw head shouldn't touch the bone completely to preserve the polyaxial capability of the screw then the screwdriver was removed and the polyaxial movement of screw was tested by moving the screw extension.

9. Rod Measuring and contouring and attachment to the rod holder and insertion The Rod must confirm to be in the screw Extensions by rotation of the screw extensions around their axis then compression or distraction was done. Before rod holder removal the rod position must be radiologically confirmed to be completely sealed within the screw head.

10. Final Tightening/Counter-Torque.

11. Screw extension removal.

12. Fascia and skin closure.

\section{Results}

Our study entails a prospective Cohort Study with preliminary results of 40 patients with Dorsolumbar fracture AO type A from June 2018 to November 2019 carried out in the orthopedic departments, Aswan and Assiut university hospitals with percutaneous fixation and follow up for 6 months up to one year. Depending on the patient's condition, the time between trauma and surgery varied from twelve to twenty-four hours, with a mean 18 hours with an SD of \pm 12.54 hours. The operative time ranged from 50 to 85 minutes with mean 65.83 minutes and SD of \pm 11.65 minutes, The preoperative Cobb angle varied from 13 to 22 degrees, with mean 18.17 and $\mathrm{SD} \pm 5.58$, the Immediate postoperative cobb angle $(9.5+1.75$ degrees $)$ which indicate significant correction of kyphosis(P-value=0.001). There wasn't any significant difference between postoperative cobb angle and final follow up cobb angle measured at 6 months postoperative which indicates stable fixation without correction loss ( $\mathrm{p}$-value $<0.001$ highly significant). Blood loss ranged between 40 to $70 \mathrm{cc}$ with a mean of $55.25 \mathrm{ccs}$ and SD of \pm 23 .36. All patients had no intraoperative complications only four laterally malpositioned screws without neurological deficit. All cases were ambulated 6 hours after surgery. All cases were ASIA score (E) preoperatively and postoperatively until the final followup. Postoperative hospital stays ranged from ( 12 to 24 hours), with a mean 18 hours and a standard deviation of 6.72 hours. As regarding the Oswestry disability index at 6 months follow up all our patients ranged from (8-13), with mean 10.25 and $S D \pm 3.2$ this means minimal disability and the patient can cope with daily living activities.

\section{Discussion}

In this study, we used the percutaneous pedicle fixation technique for fixation of type AO type (A) dorsolumbar fracture. patients were assessed clinically using the Oswestry Disability Index the final outcome ranged from 8-13, with mean 10.25 and $\mathrm{SD} \pm 3.2$ this means (minimal disability) and the patient can cope with daily living activities, better than the results published by Wei et al. [7], reported average of $34.1 \%$ (moderate disability). We compare our results with the literature as presented in Table 1. AS regarding Radiological evaluation, we had no significant loss in Cobb's angle at the final follow up in our study. Lee et al. [8] reported a loss of reduction of about 3.1 degrees in the percutaneous fixation technique [8]. As regarding screw displacement we found that only Four of 175 screws inserted were laterally displaced with no neurology or vascular complications, Pelegri et al. [9] reported that out of 50 screws the rate of displacement was only $3.8 \%$, in one case only open revision was done due to the presence of neurology. $\mathrm{Ni}$ et al. [10] reported that out of 104 screws the rate of displacement was 6.7, but there was no neurology. The time of procedure ranged from (50 to 85 minutes). Merom et al. [11] performed a short segment percutaneous fixation within 73 to 85 minutes. Ni et al. [10] performed a short segment percutaneous fixation within 70 minutes. Schmidt et al. [12] performed a short segment percutaneous fixation within 47 minutes.

As regarding infection, we had no infection in this study, this agrees with Merom et al. [11] \& Schmidt et al. [12]. Ni et al. [10] reported that there was only one case with a superficial infection that was treated only with antibiotics out of 36 cases operated percutaneously. Palmisani et al. [13] reported only one case of infection out of 64 cases of percutaneous fixation and was treated by the removal of the instruments.

As regarding blood loss, we had no significant blood loss varied from 40 to $70 \mathrm{cc}$ with mean $55.25 \mathrm{ccs}$ and SD of \pm 23 .36. Ni et al. [10] reported $75 \mathrm{ml}$ blood loss in 36 percutaneous fixation cases. The number of c- arm views ranged from 22_54 picture per case with mean 30.92 picture per case and SD of \pm 6 picture the number of images decreased significantly as we no longer use c-arm for each step we only use it to confirm the steps we became familiar with. 


\section{Statistical Analysis}

Data entry and data analysis were done using SPSS version 19. Data were presented as numbers, mean, standard deviation. An independent sample t-test was used to compare quantitative variables between groups. Pearson correlation was done to measure the correlation between quantitative variables.

\section{Conclusion}

From the result of this study, we concluded that percutaneous fixation of Thoracolumbar fracture Ao type A without neurology is a safe reliable technique with the following advantages minimally invasive with less tissue dissection, stable fixation, a small amount of blood loss, decreased hospital stay and hospitalization cost, early rehabilitation and return to daily activities.

\section{References}

1. Magerl F (1984) Stabilization of the lower thoracic and lumbar spine with external skeletal fixation. Clin Orthop 189: 125-141.

2. Mathews HH, Long BH (1995) Endoscopy assisted percutaneous anterior interbody fusion with subcutaneous superficial internal fixation: evolution of technique and surgical considerations. Orthop Int Ed 3: 496-500.

3. Lowery GL, Kulkarni SS (2000) Posterior percutaneous spine instrumentation. Eur Spine J1: 126-130.

4. Mobbs RJ, Sivabalan P, Li J (2011) Technique, challenges and indications for percutaneous pedicle screw fixation. J Clin Neurosci 18(6): 741-749.

5. Phan K, Rao PJ, Mobbs RJ (2015) Percutaneous versus open pedicle screw fixation for treatment of thoracolumbar fractures: systematic review and meta-analysis of comparative studies. Clin Neurol Neurosurg 135: 85-92.

6. Sebaaly A, Rizkallah M, Riouallon G, Wang Z, Moreau PE, et al. (2018) Percutaneous fixation of thoracolumbar vertebral fractures. EFORT Open Reviews 3(11): 604-613.

7. Wei FX, Liu SY, Liang CX, Li HM, Long HQ, et al. (2010) Transpedicular fixation in the management of thoracolumbar burst fractures: monosegmental fixation versus short-segment instrumentation. Spine 35(15): E714-720.

8. Lee JK, Jang JW, Kim TW (2013) Percutaneous short-segment pedicle screw placement without fusion in the treatment of thoracolumbar burst fractures: is it effective? A comparative study with open short-segment pedicle screw fixation with posterolateral fusion. Acta Neurochir (Wien) 155(12): 2305-2312.

9. Pelegri C, Benchikh El Fegoun A, Winter M, Brassart N, Brossard N, et al. (2008) Percutaneous fixation of lumbar and thoracolumbar fractures without neurological involvement: surgical technique and preliminary results. RCO 94(5): 456-463.

10. Ni WF, Huang YX, Chi YL, Xu HZ, Lin Y, et al. (2010) Percutaneous pedicle screw fixation for neurologic intact thoracolumbar burst fractures. J Spinal Disord Tech 23(8): 530-537.

11. Merom L, Raz N, Hamud C, Weisz I, Hanani A (2009) Minimally invasive burst fracture fixation in the thoracolumbar region. Orthopedics 32(4): 273-278.

12. Schmidt OI, Strasser S, Kaufmann V, Strasser E, Gahr RH (2007) Role of early minimal-invasive spine fixation in acute thoracic and lumbar spine trauma. Indian J Orthop 41(4): 374-380.

13. Palmisani M, Gasbarrini A, Brodano GB, De Iure F, Cappuccio M, et al. (2009) Minimally invasive percutaneous fixation in the treatment of thoracic and lumbar spine fractures. Eur Spine J 18: 71-74. 